\title{
Questions about Network Dynamics: Characteristics, Structures, and Interactions
}

\author{
Wesley J. Johnston \\ CBIM RoundTable Professor of Marketing \\ Center for Business and Industrial Marketing \\ J. Mack Robinson College of Business \\ Georgia State University \\ Atlanta GA 30303 \\ USA
}

Linda D. Peters

Senior Lecturer in Marketing

School of Management

University of East Anglia

Norwich, Norfolk NR4 7TJ

United Kingdom

\author{
Jule Gassenheimer \\ Professor of Marketing \\ Crummer School of Business \\ Rollins College \\ Winter Park FL 32789 \\ USA
}

All correspondence should be addressed to the first author at Georgia State
University

Telephone 404 651-4186

Facsimile 404 651-4198

\begin{abstract}
Hakansson and Ford (2002) raised some fundamental, yet essential, questions regarding networks. Specifically, they asked "What is a network?" and "How should companies interact in business networks?" By raising and examining these questions the authors demonstrate a number of paradoxes intrinsic to the nature of business networks for practitioners. In an attempt to continue this analysis of networks and the conundrums they present to managers and their companies, this paper raises further questions about networks. The questions address yet unanswered issues regarding network characteristics, interactions, structures and their associated dynamics. The speculation regarding these questions leads the reader further into the realm of managing within networks and the concomitant realization of markets as networks.
\end{abstract}




\section{Characteristics and Structures of Networks}

One of the most frequently cited, and measured, characteristic of social networks is that of communication. Communication is often referred to as the "glue" which binds together network interrelationships. Indeed, Samli and Bahn (1992) conceptualized a marketplace as a dynamic communication network, and attempted to identify defining features and dimensions of such networks. This definition of a market was a significant departure from prior categorizations that tended to partition markets according to geography, economic processes and exchange, demand, or consumer characteristics (Samli and Bahn 1992), and highlights four key traits of markets, they are:

- Dynamism

- Participant specificity

- Under the influence of complex versus simple dichotomy

- Determined by the dichotomy of core versus periphery

They differentiate between simple and complex network structure dynamics based on the structure of the buyer and seller balance. In a simple network there are a few buyers and sellers (or interactionists) that constitute the entire market. This would be typical of inter and intra organizational networks. Entry or withdrawal of sellers (or interactionists in the context of organizational networks) could affect the existence and nature of the market. In addition, these participants have the ability to control the market system by changing or limiting it to their best advantage (i.e., collusion). Communication is the simple mechanism used to change or limit such networks.

In complex networks, there are an abundance of buyers and sellers who engage in many levels of communication. The Internet is typical of such networks (Johnston et al. 2000). Sellers communicate with each other, buyers communicate with each other, and buyers and sellers communicate. Thus, the entry or withdrawal of individuals has very little impact on the communication network if it is close to equilibrium. On the other hand, withdrawal on just one buyer or seller in a business-to-business network can cause dramatic realignment as the network attempts to regain equilibrium and readjust the relationships fractured by the exiting firm (Young and Johnston 2005). Samli and Bahn (1992) propose that the total area of the market is a key factor in the market's complexity, and that the greater the space within which the market prevails the more complex it is. However, they recognize that markets are not simply defined by geographical locations, people, or forces that influence the demand and supply conditions. They cite Weber in defining a market as a situation in which different parties own commodities and services that are desired by others and in which there is communication among parties.

Another approach to characterizing networks is that of Luke et al. (1989) who cite Weick in highlighting the extent to which network participants are tightly or loosely coupled. Between organizations, some merge with others into tight bureaucratic structures, while others enter into more loosely coupled multi-organizational arrangements which maintain each organization's separate legal identity while at the same time functioning as interdependent wholes. They call such networks "quasi firms". They observe that such loosely coupled forms may be typically found in industries such as construction, where a specialized and autonomous group of workers, a relatively high degree of task complexity, and a high degree of uncertainty come together. Another example from our own experience of an industry where the quasi firms are common is in motion picture production. Thus, this research group has come to call this temporary formation of well structured networks the "Hollywood" model for network formation. One of the dynamics Luke at al. observe in such loosely coupled forms is the need to balance shared objectives against the need to preserve highly valued autonomies.

The extent to which they are designed to achieve strategic purposes, versus other less strategic purposes, classifies such loosely coupled forms. In order to assess the extent to which these purposes are considered strategic, they proposed two dimensions: that of the "importance" and that of the "permanence" of a shared interorganizational purpose. Therefore, the importance that 
a particular purpose or goal has for each network partner, and the relative time-scale (or longterm orientation) of the network collaboration provide the basis for our first proposed network question:

Q1. Is the network characterised by tighter or looser coupling between network partners? In other words, how important is the collaboration to the survival of each participant, and is the reach of such interorganizational linkages designed to serve a long-term purpose?

Borders et al. (2001) recognize this link between strategic purpose and new organizational forms. They stress the central role of cooperation as an essential business strategy, and highlight the role of electronic commerce in developing such networks. As they state, electronic commerce "...is a technology and a paradigm not of dyads but of networks. ...More and more, managers will find themselves working within a network - a group of actors loosely and temporarily bound by the interplay of competence and opportunity." However, Xie and Johnston (2004) draw a distinction between operational cooperation using electronic commerce technologies such as EDI and strategic alliances, which are characterized by aspects such as exclusivity and nonimitability. They cite Zinn and Parasuraman's typology of strategic alliances as composed of both dimensions of scope (the range of services included in the alliance) and intensity (the extent of direct involvement). Such network alliances are dynamic, change over time, and the essence of the communication throughout the network is influenced by environmental factors such as technological advances (Samli and Bahn, 1992). In fact, Weick and Roberts (1993) postulate that because of their fundamental reliance on participant interrelationships, network forms of organization will have more capacity for the development of a "collective mind" than other forms (M, U, and matrix).

Nevertheless, not all instances of interdependence are constructive, nor mutually beneficial (Borders and Johnston 2000:102 citing Tjosvold). They stress that in many instances, the existence of inappropriate interdependence and interaction results in inadequate exchanges of resources that can "... disrupt basic processes, interfere with productivity, delay the completion of projects, and restrict relevant information that results in costly and unnecessary programs". As Johnson et al. (2004) point out, not all interorganizational relationships can or should be close and collaborative, as certain relationships may not merit the resources required to maintain them. Ritter, Wilkinson, and Johnston (2004) argue that management and control within cooperating networks may be contingent upon different types of relationships and network management situations, including those when they are in a powerful and controlling position, those when they are the subject of other control, and those in which multiple parties have strong influence over each other. They stress that network management is a two-way process, and is primarily about managing the interactions with others in the network, not about managing network partners as such. Implied in this two-way process is the influence that different levels of network interaction may have on each other. Interactions at the individual participant level may influence, and be influenced by, interactions at the team and/or organisational level. Therefore, we ask the following question.

\section{Q2. What is the appropriate level of analysis in examining networks?}

The dynamic nature of network interactions has presented researchers with challenges, both conceptual and empirical (Holmlund 2004). Samli and Bahn (1992) recognise that in seeking to understand the establishment and working of networks, a research approach is needed which not only considers the definition and structure of such networks, but also recognizes that this network context is 'constructed' into the social processes present in the network. This concern is central in structuration theory (Giddens 1984) which examines the interplay of structure and action in creating and maintaining social systems. "Structurationists see social interaction as a kind of 
prism through which individual and communal ends are refracted to create social reality. Organising consists of an unresolved dialectic between autonomy and interdependence, agency and constraint" (Contractor and Eisenberg 1990:147).

Structuration theory asserts that individuals are active agents with the capacity to transform their setting through action (Giddens, 1984). The theory equally recognizes the strong influence of external structures on behavior, and as pointed out by Huff et al. (2000) structuration theory provides a means of integrating an interpretive, cognitive perspective with structural approaches. Berends et al. (2003:1041) state that structuration is "the construction and reconstruction of structure by the interaction of knowledgeable actors." Thus, individual knowledge is situated within a larger social context. It highlights that knowledge is distributed in nature, in that only a part of the available knowledge will be shared by all organisational members (Berends et al. 2003:1042).

Pozzebon (2004:253) highlights the fact that Giddens radically reformulated traditional notions of both agency and structure. "To solve the dualism between structure and agency; Giddens departed from the conceptualization of structure as having some given or visible form. Structure is what gives form and shape to social life, but it is not itself that form and shape." Structure only exists in and through the activities of human agents (Giddens, 1984). Similarly, he departed from the idea of agency as something just 'contained' within the individual. "Agency does not refer to people's intentions in doing things but more to the flow of people's actions." (Pozzebon 2004:253)

According to Berends et al. (2003), structuration theory implies that the notion of agency, of the individual acting person, has to be reworked. They stress that the individual is not an absolute given, but that individuals necessarily draw upon pre-existing rules and resources (that is, a preexisting structure). Of course, in order to draw upon these pre-existing rules and resources actors have to be 'knowledgeable' of them. Structuration does not imply that actors are slaves of existing structures, they do in fact have the power to 'act otherwise'. As Berends et al. (2003:1040) point out, the means whereby systems are reproduced, the interactions of knowledgeable actors, contain within them the seeds of change. However, they also point out that ascribing knowledgeability to actors does not imply that they are omniscient about their motives, conditions and consequences of their actions. There may be 'unacknowledged preconditions' and 'unintended consequences of action', which form the bounds of knowledgeability (Giddens 1984: 294) and which play an important role in the production and reproduction of structure.

It is the inseparable link between structure and agency, known in structuration theory as the duality of structure, which distinguishes the structurationist approach. As Giddens states: "Agents and structures are not two independently given sets of phenomena ... but represent a duality ... the structural properties of social systems are both medium and outcome of the practices they recursively organize" (Giddens, 1984:25).

One important contribution of structuration theory is to address the problem of levels of analysis. "Structuration theory helps to bridge micro and macro levels of analysis. Individuals perform actions in the name of groups or organizations. When these actions become a constituent element in the relations between and organization and external bodies, they move to an even higher level of social process. Micro practices begin to be shared, reproduced, routinized, and, finally, institutionalized. Similarly, institutionalized practices, norms and rules at the macro level (i.e., industry) influence everyday activities, constraining or stimulating certain individual perceptions and choices" (Pozzebon 2004). This duality of structure, and the interrelationship between network levels, raises the following questions.

\section{Q3. How does work get done in groups?}


Q3a. Why does similar work get done differently in different places?

This multi-level approach may help to address these questions. For example, at one level "Best practices" can be seen as the benchmarking of highly successful processes - where new concepts and methods are examined and integrated into practice through processes that involve individuals, teams, and larger organisational constituents. On the other hand, it may simply be replicated as just "things that worked someplace else", where more limited, fragmented, and isolated understanding is developed. This has key implications for the transference of best practices within and between networks.

Perlow et al.'s (2004) nested theory of structuration, concentrating on theories of fit (contingency, configuration, and congruence) is a key issue in organizational learning and highly relevant here. How fit is achieved becomes the focus of research into the dynamics of organizational networks.

Q4. How might the notion of "fit" be relevant in characterizing network structures and interactions?

Exploring patterns of interaction at different levels of analysis can help to identify how fit is achieved. "...from a structuration standpoint, organizational structures would be said to fit with each other to the extent that they reinforce and are reinforced by the same patterns of interaction. In other words, for two organizational structures to fit with each other, they both must simultaneously be in their own unique mutually reinforcing relationship with the same pattern of interaction (Perlow et al 2004:533)". They cite areas such as team learning, coordination, and knowledge sharing as interaction patterns which could be understood by investigating how fit is achieved.

One further way in which networks may be characterised is posed by Samli and Bahn (1992), who put forward five dimensions thought to be important for analyzing a network (or more specifically, a communication network):

- Spatial - analysis of the point or area where communications take place

- Temporal - analysis of the timing and duration of the communications system

- Behavioral - analysis of the behavioral patterns of the participants in the communication network

- Socio-economic - analysis of the impact of social values, social structure, and economic conditions on the market network

- Functional - analysis of inherent variables influencing the market communication network

Given that each of these dimensions could be explored from different levels of analysis within a network context, we have here a useful framework for characterizing and exploring the nature of network dynamics, such as communications and their outcomes in both network functioning and organizational performance, as they relate to network structure.

Having reviewed several perspectives regarding the characteristics and structuring of networks, we now go on to explore the nature of network interactions.

\section{Understanding Network Interactions}

Why do participants in a network interact? Often, it is in order to share knowledge and to build new understandings. In terms of how knowledge networks operate, Haythornthwaite (2002) states that outside instructional settings collaborative learning may be the norm, and the model of the single information disseminator may not apply. "Learning groups may not be guided by a single individual. Instead they may learn by sharing information among themselves, building a 
repertoire of knowledge within the network. This type of collaborative learning is common when product teams set out to create something new, or when scholars seek to expand and build on a complex area of knowledge" (Haythornthwaite 2002:168 citing Scardemalia \& Bereiter, 1996). He goes on to stress that for these learners, it is communication among network members that matters most. He posits that in order to support these types of learning groups, it is necessary to go beyond consideration of information dissemination to consideration of mutual exchanges among learners, exchanges that are also essential building blocks of communities. However, the question of where to draw organisational boundaries in such knowledge networks also impacts knowledge transfer and subsequent organisational performance.

In sharing knowledge and building new understandings, the "meaning" of what is shared is not an objective or isolationist concept. It entails interpretation (often linked to prior experience and expertise) and is context reliant. "Organizational learning, like individual learning, involves the development of new and diverse interpretations of events and situations. Unlike individual learning, however, collective learning also involves developing enough consensus around those diverse interpretations for organized action to result (Fiol 1994)".

Fiol separated the notion of consensus into two component parts: consensus around interpretations embedded in the content (the labels people use to convey their picture of reality), and consensus in the framing of communications (how something is expressed, the form people use to construct a picture, regardless of its content, e.g., rigid or flexible perceptions of an issue). She noted that people may hold very different pictures of reality and still agree on the way they frame them. "It is thus possible for groups to simultaneously agree and disagree, an essential component of collective learning ... meanings can be simultaneously diverse and shard across individuals. Consensus may develop around one dimension of meaning and not around another (Fiol 1994)."

This leads us to the understanding that actors in networks can simultaneously agree and disagree, creating an essential ingredient of collective learning. In order for broad and ambiguous ideas to effectively "unify" people around multiple meanings of issues or events must share the broad framing of the issues. Even if individuals disagree about their interpretive pictures (or communication content), they may still converge around a frame that is broad enough to encompass those differences (Fiol 1994). According to Barrett et al. (2004) knowledge sharing within communities is often easier than it is between communities, due to the shared symbols and norms of behavior. Thus we can posit that the structural features of a network may well influence this process of consensus building, both in the interpretation of content and the framing of information. Therefore we ask the following question.

Q5. How do network structure characteristics influence consensus building, learning, and their associated network performance outcomes?

Q5a. How does learning differ given different network structures (e.g. the extent to which firms in the network are loosely or tightly coupled)?

The notion of meaning and structure in team working may help explain the self-organizing processes which Ritter, Wilkinson, and Johnston (2004) propose are at the heart of networks as complex adaptive systems. They see the management of networks as emerging from the interactions taking place among individuals in the network. No individual (or individual firm) can control or direct the network. Collaboration is therefore necessary, as firms within networks are not free to act according to their own aims or agendas and must collaborate in order to achieve their goals, and the goals of the network (Batt and Purchase, 2004). Fiol's (1994) key proposition was that consensus building in networks involves aspects of both shared content and the framing of information. It recognised that meanings can be simultaneously diverse and shared across individuals in the network, and thus consensus in not a simple unidimensional construct. We can 
picture this as a simple Venn diagram, where the overlap of these two aspects is the extent to which the meaning of both framing and content are shared. One way of facilitating such meaning is through shared symbols and norms (See Figure 1).

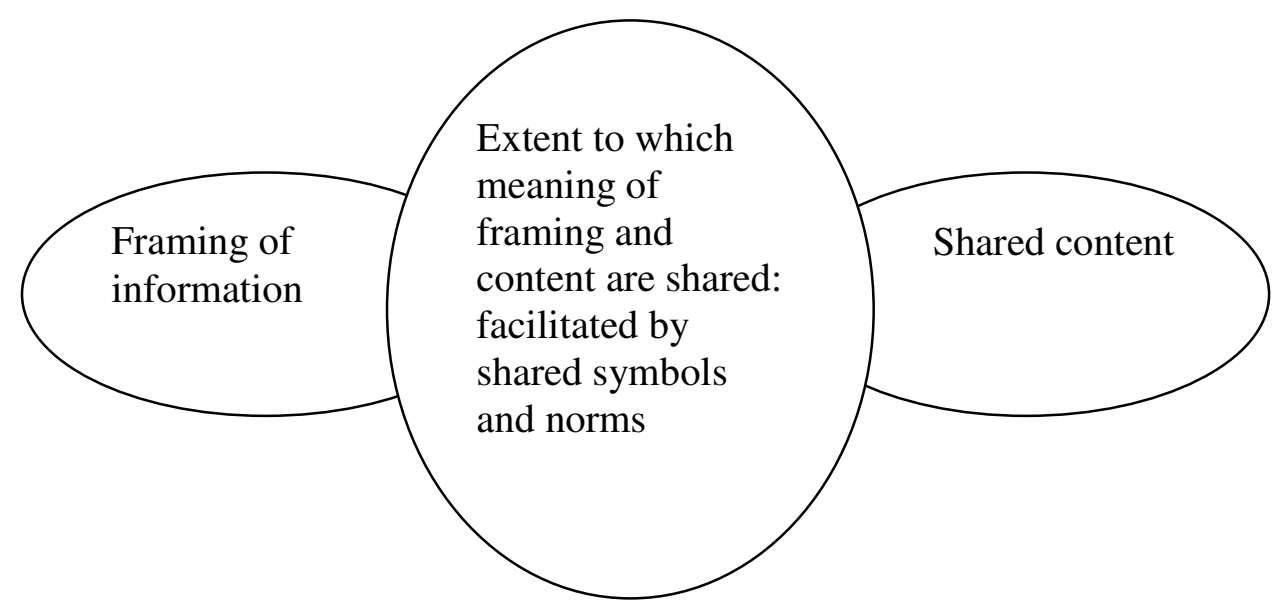

Figure 1. Process of Organizational Learning in a Network

As we mentioned in our discussion of network characteristics, one of the features we observe in loosely coupled network forms is the need to balance shared objectives against the need to preserve highly valued autonomies. These shared objectives are a key feature in the building of social capital by network participants, where value creation is seen not simply the accomplishment of individuals but as stemming from the networks in which such individuals are embedded. Researchers such as Burt (1992) have argued that network linkages enable and constrain the flexibility, autonomy, and consequently the effectiveness of organisational members. In terms of network interactions, we can see that this balance of shared objectives and autonomy relates to Burt's notion of structural holes, and to the impact of strong and weak ties. Structural holes and positioning in the network impact what is learned and who learns it and the impact it has on the organization's operations. If learning takes place at the wrong level it may never reach the place in the organization where the information will be beneficial or change policy - this is related to the heedful interrelating of knowledge management. It may also relate to the "voice" literature if we assume that what they discuss as the process of resolution of disagreement mirrors the process of developing shared objectives in networks. Therefore, the means through which interactions take place in a network would be expected to influence the dissemination of knowledge in that network. Thus we ask the following question.

\section{Q6. What are the network mechanisms that influence the transfer of knowledge?}

In teamworking, the perceptions or meanings that members attach to teamwork may be explained by linking them to the structure of the team (Cott 1998). Cott defines the meaning of teamwork as the interpretations or perceptions of individual team members as to the effect of being part of a team for themselves personally and for their work, and the structure of the team as the patterns of relationships amongst team members that underlie the organization of the team. As she points out, meanings are developed through social interaction and through the interpretation made by the individual of their situation. 
On the other hand, the structure of the team may be conceptualized as a network of different kinds of relationship or ties among team members as they go about their work. Such ties may be more or less dense, complex, or reciprocal. According to Haythornthwaite (2002:166) the advantages of strong and weak ties are fairly well accepted. "Strong ties provide timely access to information circulating the network, and those with whom we are strongly tied are more motivated to share information with us. However, since these individuals tend to travel in the same social circles that we do, the information they have may be redundant with that available form others within our close network. By contrast, those with whom we are weakly tied are likely to travel in different circles form our own, thereby opening up access to new information. However, our infrequent contact with these others, and their lack of motivation to share with us may make for less timely receipt of information." Clearly, features of a network such as the connections which are present or absent, their strength, their direction, and their time-frame must influence the learning processes in networks. In addition, such network features may influence these learning processes differently depending on the network level under review. Therefore, we ask the following questions.

\section{Q7. What are the main features/dimensions of interdependence in network structures?}

Q7a. Might the perceived lifetime of the network (one-off project versus VAMP) affect learning processes?

Q7b. Can the perceptions of network outcomes differ at different network levels (i.e., one-off projects at one level are also seen as part of longer term relationship at another level)?

Focusing on the nature of the interaction itself, a useful analogy of interactions may be the found in the notion of intertwining (Robey et al, 2003), such as the weaving, braiding and entangling of filaments such as silk, wool of hair. Where different layers (or parties) of a network co-exist, their interactions intertwine. Intertwining augments the performance of individual elements, and forms a reciprocal involvement between network participants. Four aspects of intertwining are considered by Robey et al (2003):

- Reinforcement, where the relationship is strengthened by the addition of an element that amplifies the effect of another element (i.e. more filaments are stronger than fewer). This is related to the notion of redundancy in systems design.

- Complementarity, where each element offers unique characteristics that may compensate for weaknesses (i.e. one element provides flexibility while the other provides strength).

- Synergy, where one element interacts with the other to produce effects that exceed the effects from the individual element alone (i.e. where IT enables continuous inventory replenishment).

- Reciprocity, where elements are mutually interdependent (i.e. where work processes require information from more than one network node).

These aspects of intertwining help us to examine the nature and appropriateness of network interactions. Understanding these interactions may then raise the question of desirability in network interactions. These relations involve ongoing negotiation between team members through a series of conflicts and compromises as they attempt to establish a basis for their concerted action (Cott 1998). However, Cott stresses that this negotiation must also take account of differences in authority, power, and influence. This theme is also apparent in what Meindl et al. (1994) term "interpretive dominance". Interpretive dominance conceptualizes belief 
systems as an active area, where interest groups compete to impose their views on others is the subject of substantive interest. Interpretive dominance also relates to the voice we use when disagreements over differences of opinion arise. We then may ask the following question.

\section{Q8. When is interdependence appropriate and/or constructive?}

Another way to conceptualize network interactions is to examine the structure of the interconnections within the network. The core of any network approach is that reality should be primarily conceived and investigated from the view of the properties of relations between and within units instead of the properties of these units themselves. In general, network analysis focuses on the relationships between people and organizational units instead of on characteristics of managers and companies. We may then ask what kind of typology would best serve an investigation of network interactions.

\section{Q9. What would be a useful typology of network interactions?}

The interconnectedness of interactions is also important. When a series or stream of interactions is perceived and assessed as a unit by the counterparts in the relationship, it forms a natural entity (Holmlund 2004). When interactions at different hierarchical levels are seen as interconnected then these separate events are perceived as one whole, and assessments may be drawn accordingly by those interacting (Holmlund, 2004). Thus, it may be difficult to distinguish between internal and external firm activities. The interfacing of intra and inter organizational relationships is an important strategic issue confronting management (Ritter et al., 2004). Ritter et al. recognize that management in business networks arises at the individual, group or business unit level and that these levels are interrelated.

\section{Conclusion}

In this paper we have raised several questions regarding the characteristics and structures associated with networks, and have looked a key issues in understanding network interactions. By raising and examining these questions we have sought to demonstrate a number of paradoxes intrinsic to the nature of business networks for practitioners. In an attempt to continue this analysis of networks and the conundrums they present to managers and their companies, this paper raises further questions about networks. In particular, we focus upon the dynamic nature of network interactions, the importance of multiple levels of analysis in understanding network dynamics, and the need for more complex models when seeking to describe the workings of networks in relation to consensus building and participant interactions. Our speculation regarding these questions leads us to into realm of managing within networks and the concomitant realization of markets as networks.

\section{References}

Barrett, Michael., Cappleman, Sam., Shoib, Igamila and Walsham, Geoff (2004) "Learning in Knowledge Communities: Manageing technology and context", European Management Journal, vol. 22. no. 1 (February) pp. 1-11

Batt, Peter J. and Purchase, Sharon (2004) "Managing collaboration within networks and relationships", Industrial Marketing Management, vol 33, pp 169-174

Borders, Aberdeen Leila., Johnston, Wesley J. and Rigdon, Edward E. (2001) "Beyond the Dyad: Electronic Commerce and Network Perspectives in Industrial Marketing Management", Industrial Marketing Management, vol 30, pp 199-205 
Borders, Aberdeen Leila and Johnston, Wesley J. (2000) "Electronically Wiring the Network: Efficient Consumer Response (ECR), Electronic Data Interchange (EDI) and Interdependence", ACR, vol 8, no. 1, pp 100-109

Contractor, N., \& Eisenberg, E. (1990) "Communication Networks and New Media in Organizations", in J. Fulk \& C. Steinfield (Eds.), Organizations and communication technology, London: Sage Publications.

Cott, Cheryl (1998) "Structure and Meaning in Multidisciplinary teamwork", Sociology of Health \& Illness, vol 20, no 6 pp 2-16

Fiol, C. Marlene (1994) "Consensus, Diversity, and Learning in Organizations", Organization Science, vol 5, no 3 (August), pp 403-420

Giddens, A. (1984) The constitution of society: outline of the theory of structuration, Chicago: Polity Press.

Hakansson, Hakan, and David Ford (2002) "How should companies interact in business networks?", Journal of Business Research, vol 55, pp 133-139

Haythornthwaite, C. (2002) "Building social networks via computer networks: Creating and sustaining distributed learning communities". In Building Virtual Communities: Learning and Change in Cyberspace, K.A. Renninger \& W. Shumar (Eds) Cambridge: Cambridge University Press, pp. 159-190

Holmlund, Maria (2004) "Analyzing business relationships and distinguishing different interaction levels", Industrial Marketing Management, vol 33, pp 279-287

Johnson, Jean L., Sohi, Ravipreet S., and Grewal, Rajdeep (2004) "The Role of Relational Knowledge Stores in Interfirm Partnering", Journal of Marketing, vol 68 (July), pp 21-36

Johnston, Wesley J., Borders, Aberdeen Leila, and Edward E. Rigdon (2000) "Electronic Marketing and Purchasing". In Interactions, Relationships and Networks: Managerial Issues, $16^{\text {th }}$ IMP Conference Proceedings, Bath, U.K.

Luke, Roice D., Bergun, James W., and Pointer, Dennis (1989) "Quasi Firms: Strategic Interoganizational Forms in the Health Care Industry", Academy of Management Review, vol 14, no 1, pp 9-19

Meindl, James R., Stubbart, Charles and Porac, Joseph F. (1994) "Cognition Within and Between Organizations: Five Key Questions", Organization Science, vol 5, no 3 (August), pp 289293

Perlow, Leslie A., Hoffer Gittell, Jody and Katz, Nancy (2004) "Contextualizing Patterns of Work Group Interaction: Toward a Nested Theory of Structuration", Organization Science, vol. 15, no 5 (September-October), pp. 520-536

Pozzebon, Marlei (2004) "The Influence of a Structurationist View on Strategic Management Research", Journal of Management Studies, vol 41, no 2 (March), pp 247-272

Ritter, Thomas., Wilkinson, lan F. and Johnston, Wesley J. (2004) "Managing in complex business networks", Industrial Marketing Management, vol. 33, pp 175- 183

Robey, D., Schwaig, K. S. and Jin, L. (2003) "Intertwining material and virtual work", Information and Organisation, vol 13, pp 111-129 
Samli, A. Coskun and Bahn, Kenneth (1992) "The Market Phenomenon: An Alternative Theory and Some Metatheoretical Research Considerations." Journal of the Academy of Marketing Science, vol. 20 (2), pp 143-153

Tian Xie, Frank and Johnston, Wesley J. (2004) "Strategic alliances; incorporating the impact of e-business technological innovation", Journal of Business \& Industrial Marketing, vol 19, no3, pp 208-222

Weick, Karl E. and Roberts, Karlene H. (1993) "Collective Mind in Organizations: Heedful Interrelating on Flight Decks", Administrative Science Quarterly, vol 38, pp 357-381

Young, Louise and Johnston, Wesley J. (2005) "Dynamic Networks: Towards a theory of balance in relations and networks", working paper based on an IMP conference presentation, at the $16^{\text {th }}$ IMP Conference, Interactions, Relationships and Networks: Managerial Issues, Bath U.K., 2000. 